\title{
The transition to consultant: Identifying gaps in higher specialist training 䇺
}

\author{
Authors: Sophie Flavell, ${ }^{A}$ Angela Robinson ${ }^{B}$ and Jane Dacre ${ }^{C}$
}

\section{Background}

New consultants consistently feel better prepared for the clinical rather than non-clinical aspects of their role. However, deficiencies in generic competencies have been linked to burnout and patient complaints. This study explored how higher specialty training prepares doctors for the transition to consultant in genitourinary medicine.

Results

New consultants felt less prepared for non-clinical aspects of their role. Prior practical experience was the greatest influencing factor in levels of preparedness, with increased responsibility and leadership driving deeper learning.

Observation of others helped individuals develop a professional identity but also learn about the wider processes within their service. The learning environment positively influenced preparedness but highlighted a need for dedicated time to learn non-clinical aspects.

\section{Conclusion}

To ensure future trainees feel prepared for the non-clinical aspects of the consultant role, practical experience of nonclinical areas with high levels of leadership and responsibility within a supportive learning environment is essential.

KEYWORDS: Transition, medical education, preparedness, genitourinary medicine, non-clinical skills

DOI: $10.7861 /$ clinmed.2020-0085

\section{Introduction}

The transition from registrar to consultant can be one of the most challenging transitions throughout a doctor's career. ${ }^{1,2}$ Higher specialty training (HST) aims to best prepare doctors for this transition. However, studies consistently show new consultants feel better prepared for the clinical rather than non-clinical aspects of their role. ${ }^{1-4} A$ perceived lack of preparedness for

Authors: ${ }^{\text {A }}$ consultant in genitourinary medicine, Nottingham University Hospitals NHS Trust, Nottingham, UK; ${ }^{\mathrm{B}}$ consultant in genitourinary medicine, Central and North West London NHS Foundation Trust, London, UK; ${ }^{\text {C }}$ professor of medical education, University College London, London, UK non-clinical competencies has been linked to burnout among new consultants. $^{5}$

Over the last decade there has been an increasing drive to incorporate non-clinical competencies within medical curricula., ${ }^{6,7}$ Fitness to practice data, patient safety reviews and complaints about doctors repeatedly highlight shortfalls in non-clinical areas, for example poor communication. ${ }^{8-10}$ As a result, the General Medical Council (GMC) have developed the generic professional capabilities framework to ensure all trainees are meeting a minimum standard for generic competencies across specialties. ${ }^{9}$

Consultant roles differ between medical specialties. However, all have in common the ultimate responsibility for patient care, team management, leadership, teaching and training. ${ }^{11}$ Within genitourinary medicine (GUM), consultants can be in stand-alone outpatient services with reduced links to the acute hospital. ${ }^{12}$

They often have high levels of management responsibilities given different funding streams, the need to write competitive tenders and provide services within reducing public health budgets. ${ }^{12}$ The GMC's 2018 national training survey showed that GUM trainees perceived HST to give them sufficient experience to meet their clinical competencies. ${ }^{13}$ The perceptions of non-clinical aspects of HST were unknown and there are no studies looking at this transition in GUM. Previous literature explores the transition from registrar to consultant within predominantly hospital-based specialties. ${ }^{1-5}$

The aim of this study was to explore new consultants' views on how HST prepares them for the consultant role, particularly around non-clinical aspects. This is important to help educators and curriculum planners further align training with the consultant role.

\section{Methods}

An exploratory sequential mixed methods study (Fig 1) was conducted. An initial qualitative phase used semi-structured interviews to explore individual perceptions. The findings informed the development of a questionnaire for the second quantitative phase.

To ensure recent HST was reviewed, new consultants who had gained their certificate of completion of training (CCT) in GUM since January 2016 were invited to participate. A purposeful sampling strategy was adopted for phase 1 to ensure this was representative from across the UK. For phase 2 a population sampling strategy was used aiming to invite everyone who fit the inclusion criteria. The maximum number of participants was 60 , using those who had gained their CCT between 01 January 2016 and February 2019. ${ }^{14}$ The actual number was likely to be 


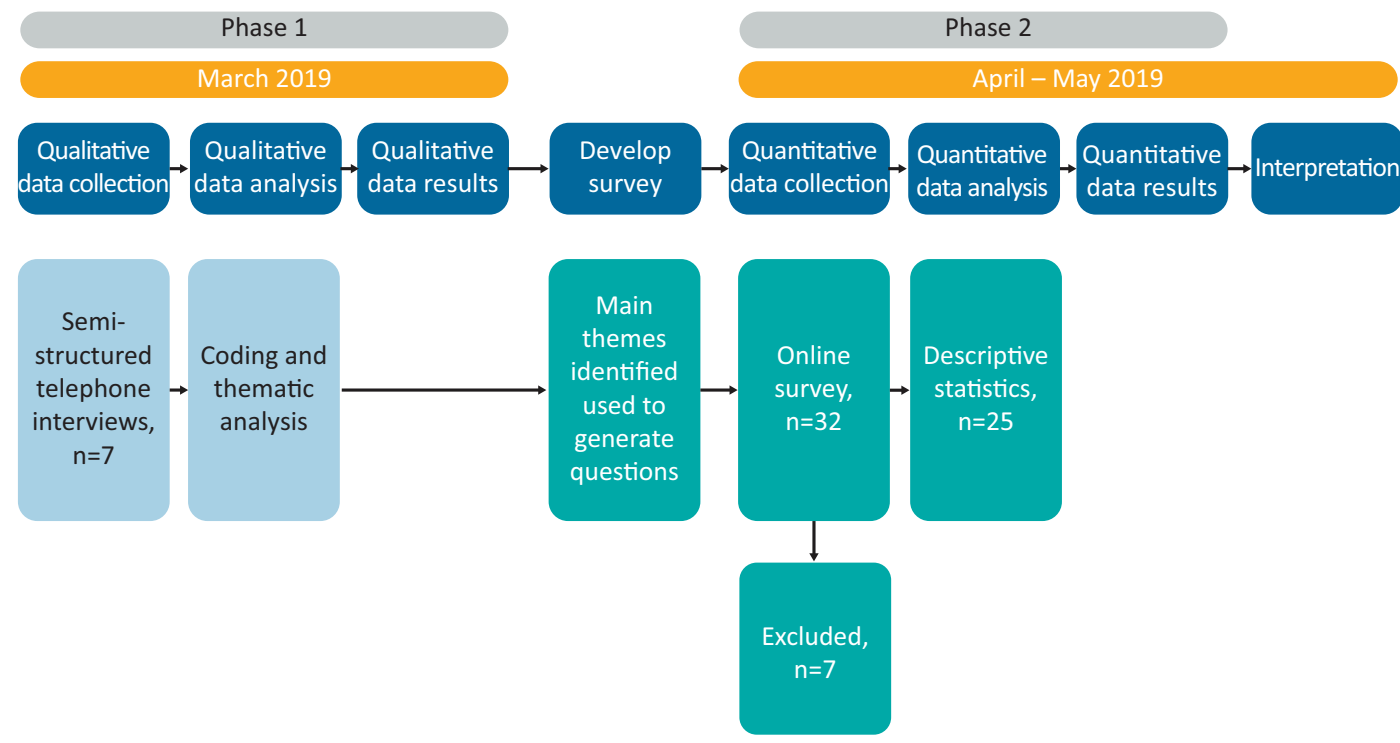

Fig 1. An exploratory sequential mixed methods study.

lower accounting for individuals who had not yet become a consultant.

A three-pronged approach recruited participants to both phase 1 and 2 of the study:

$>$ advertisements in specialty society newsletters

$>$ emails sent to the lead clinician from local departments where consultant posts had been advertised since 2015

> Twitter advertisements through the lead researchers account.

\section{Phase 1: Interviews}

Seven participants, from various locations across the UK, were recruited to phase 1 of the study. Semi-structured telephone interviews were conducted by the lead investigator in March 2019. This method was selected to ensure standardisation of questioning but also to allow some flexibility to explore tangents. Information was gathered on:

> experiences of HST and the consultant role

$>$ which aspects of the consultant role that participants felt most or least prepared for

> how HST had prepared them for the new role; focusing on the non-clinical aspects.

Several questions asked the same thing in a different way to help contribute to the validity of data.

Interview data was audio recorded with informed consent and then transcribed verbatim. The lead investigator analysed the data using thematic analysis. An inductive method was chosen to code the data, initially generating open codes and then refining these where possible. Themes and sub-themes were subsequently generated from these codes. Themes were only generated where data appeared from at least two participants thus improving the validity.

\section{Phase 2: Questionnaire}

An online questionnaire was developed in April 2019 for phase 2 of the study using the data analysed from phase 1 . The purpose of the questionnaire was to check the transferability of the qualitative findings and therefore closed questions were chosen. Multiple choice questions were used for demographic questions. Five-point, semantic differential scale questions explored participants' attitudes on preparedness for different aspects of the consultant role. Four-point, Likert scale questions were adopted for the questions exploring perceptions on the themes generated from the phase 1 data. The questionnaire was piloted by four medical professionals, within different specialties, to check comprehension and time to completion. Prior to dissemination it was also reviewed and approved by the GUM Specialist Advisory Committee.

Twenty-five participants completed the anonymous, online questionnaire between April and May 2019. The participants who underwent an interview were also invited to complete the questionnaire. Descriptive statistics were used for data analysis showing frequencies of agreement with the qualitative themes from phase 1 .

The study underwent ethical screening and was deemed exempt from full ethical review. Informed consent was gained from all participants.

\section{Results}

\section{Results: Interviews}

Seven consultants participated in the telephone interviews. Demographic data is found in Table 1.

Four over-arching themes emerged from the data:

$>$ preparedness

$>$ methods of learning

$>$ learning environment

> leadership and responsibility.

\section{Preparedness}

Participants all felt most prepared for the clinical aspects of the role. Several participants also felt well prepared for the service 


\begin{tabular}{|c|c|c|c|}
\hline Demographics & & $\begin{array}{l}\text { Phase 1, } \\
n=7\end{array}$ & $\begin{array}{l}\text { Phase 2, } \\
n=25\end{array}$ \\
\hline \multirow{3}{*}{$\begin{array}{l}\text { Working hours } \\
\text { during higher } \\
\text { specialty } \\
\text { training }\end{array}$} & Full time & 6 & 15 \\
\hline & Part time & 0 & 0 \\
\hline & $\begin{array}{l}\text { Full and part } \\
\text { time }\end{array}$ & 1 & 10 \\
\hline \multirow{3}{*}{$\begin{array}{l}\text { Time out of } \\
\text { training }\end{array}$} & Yes & 1 & 15 \\
\hline & No & 6 & 9 \\
\hline & No response & 0 & 1 \\
\hline \multirow{4}{*}{$\begin{array}{l}\text { Number of } \\
\text { consultants at } \\
\text { their current } \\
\text { service }\end{array}$} & Sole consultant & Not collected & 1 \\
\hline & $1-2$ & Not collected & 7 \\
\hline & $3-4$ & Not collected & 6 \\
\hline & $5+$ & Not collected & 11 \\
\hline \multirow{2}{*}{$\begin{array}{l}\text { Formal } \\
\text { management } \\
\text { role as a } \\
\text { consultant }\end{array}$} & Yes & 7 & 17 \\
\hline & No & 0 & 8 \\
\hline
\end{tabular}

improvement, teaching and training aspects. Participants mostly felt less prepared for the non-clinical aspects. The areas specifically highlighted were financial aspects, managing people, being a supervisor, managing conflict, being a leader, implementing change, system differences between services and managing complaints.

I think the less prepared bits are, I guess, the management side of things, really. And just understanding budgets. Participant 1

I'm not sure it exactly prepared me for handling conflict between different staff members. Participant 5

It was also widely recognised that some aspects of the consultant role are difficult to prepare for until you are in the role.

Trainees need to get a bit more experience with the handling of complaints. Obviously, complaints are often quite sensitive, they might be naming specific members of staff and things like that. So, there's got to be a balance between the training of an individual but also the maintenance and privacy and looking after your other members of staff who might have been complained about. Participant 1

\section{Methods of learning}

The data showed that people learnt through a variety of different ways: experience, observation and formal teaching. Overwhemingly, practical experience of an area during HST led to the greatest degree of preparedness where the greater the involvement the better prepared an individual felt. From a clinical perspective, acting up as the consultant had great value in giving participants confidence in their own decision making.

I think probably most useful thing I did was act up as a consultant, it was really reassuring that actually I could do it. Participant 4
Learning through observation was valuable in developing a professional identity through observation of different leadership styles.

You spend loads of time, don't you? Looking at the consultants around you going, I don't want to be like you. I want to be like you. I'll be a little bit like you, but I'm definitely not going to be like you. Participant 4

Participants described benefits of attending management meetings in seeing how services are run including an insight into financial aspects.

...they talked a lot about finance so they would do a breakdown of our finances and money that we had to save and how we were going to do that and how the directorate as a whole was working within the hospital, so it kind of really made you understand. Participant 7

While formal management and leadership teaching were valued for learning the theory, participants described it was through practical experience where the real learning occurred.

It's all very well learning the theory but it's when you put the theory into practice is when you really learn. Participant 6

\section{Learning environment}

The learning environment had a direct influence in helping prepare consultants for the role. The provision of support and opportunity from senior members of the team, particularly around non-clinical aspects, positively correlated with feelings of preparedness. The provision of opportunity from the beginning of HST was important.

The consultant who was actually looking forward for us, about what's coming in the future, what we can prepare them for. Participant 3

Participants also felt that having dedicated time to learn nonclinical aspects within their rota was valuable.

When you're a registrar it's very heavily clinical. You don't get given a session to say, let's manage this. Participant 3

\section{Leadership and responsibility}

Participants recognised the increased levels of leadership and responsibility with the consultant role. Increasing responsibility and autonomy during HST correlated with greater preparedness.

I think just because of the kind of training that I got, they very much encourage you to be autonomous and lead on things I felt that actually, even quite a lot of the management type stuff was something that - I don't know - I didn't find it as stressful as I thought it would be. Participant 4

However, sometimes it was felt that leadership opportunities were lacking in HST. It was also expressed that the level of responsibility during HST was not the same as a consultant.

\section{Results: Questionnaire}

Thirty-two participants completed the online questionnaire; 7 were excluded due to not meeting the inclusion criteria, therefore 


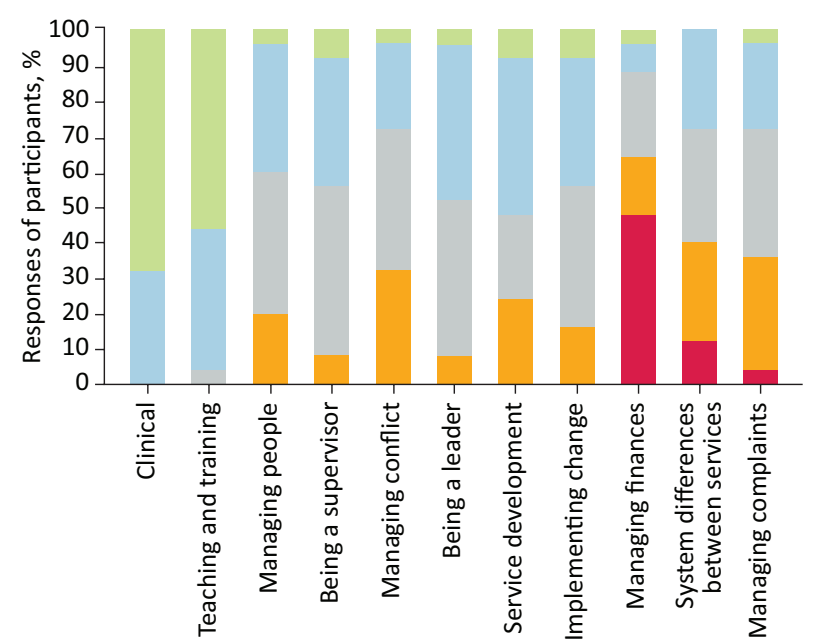

$\square 1$ (not at all well prepared) $\square 2 \square 3 \square 4 \square 5$ (extremely well prepared)

Fig 2. Levels of preparedness of new consultants for different aspects of their role.

25 participants were included in the final analysis. Demographic data can be found in Table 1 .

\section{Preparedness}

Levels of preparedness supported the findings from the qualitative data (Fig 2).

\section{Significant statements}

Questionnaire data showed that the wider population of new GUM consultants corroborated themes generated by the qualitative data (Table 2).

\section{Discussion}

This study found that new consultants felt most prepared for the clinical areas which is consistent with previous findings. ${ }^{1-5,15-17}$ Rotas tend to focus on the clinical aspects consequently giving individuals greater clinical experience. Acting up as a consultant goes further in lessening the transition because it provides an experience closer to the levels of a consultant with associated increased levels of responsibility, again reflected in another study. ${ }^{1}$

Often in studies looking at transition, all the non-clinical aspects are grouped together which, as an educator, makes it challenging to see exactly which areas need more attention. In looking at levels of preparedness, specific areas can be defined, however, this was not possible when looking at processes of learning and contextual factors.

Our study found that new consultants also felt well prepared for teaching and training and, to a lesser extent, service development aspects. This can be explained by exposure gained during HST; curricula stipulate the need for trainees to be observed teaching and to perform audits or quality improvement projects. ${ }^{18}$ Morrow et al, in contrast, found new consultants felt poorly prepared for service development. ${ }^{2}$ However, this was a decade ago and certainly, in recent years, quality improvement projects (QIP) are more popular.
The areas where new consultants felt less prepared were mostly supported by the literature: managing people, being a supervisor, managing conflict, being a leader, implementing change, managing finances, system differences between services and managing complaints. ${ }^{2-4,15,16}$ Essentially the more exposure or experience an individual had with a certain aspect, the more prepared they felt for that aspect.

Practical experience was the main process through which a deeper level of learning occurred, leading to feelings of greater preparedness for the consultant role. Practical experience helps to create knowledge, as described by Kolb's learning theory. ${ }^{19}$ It has also been shown to help with knowledge retention, particularly compared with listening or reading. ${ }^{20}$ Yardley et al has previously highlighted the importance of practical experience for workplace learning. ${ }^{21}$ Therefore, given our study findings, it is imperative that trainees are getting enough practical experience in the non-clinical aspects of the consultant role. Formal management courses are not enough for learning non-clinical aspects. ${ }^{2,4}$ There needs to be a platform to put theory into practice.

This study showed that observing senior management meetings gave individuals further insight into the running of services. This is a key part of the consultant role. Previous literature has suggested trainees are sometimes not allowed to attend the meetings and that they may be of limited benefit if they were becoming a consultant in a different trust. ${ }^{2,4}$ Based on our findings we would recommend that trainees are encouraged to attend meetings or shadow senior trust individuals.

The learning environment (the physical workplace, people, culture and systems within it) plays an important part in the learning process. One study surveyed new consultants on how the learning environment and competence-based education influenced their feelings of preparedness. ${ }^{22}$ The learning environment was the strongest predictor of preparedness for independent practice. It comes as no surprise that senior support, encouragement, provision of opportunity and feedback positively correlated with feeling prepared for the consultant role in our study. As educators, we have an impact on the learning environment and a negative one can have destructive effects. ${ }^{22}$ Providing dedicated time for trainees to learn non-clinical skills could help to further enable trainees to develop these areas. However, it is important to ensure this time has specific objectives and isn't labelled as 'management time' to ultimately be swallowed up with service provision.

We know increased responsibility and leadership within the consultant role is challenging for some. ${ }^{2,4,10}$ This study highlighted at times there was a lack of leadership opportunities during HST, which was more pronounced in non-clinical compared to clinical areas. This could be explained by lack of time or trainee confidence in taking the lead. We need to rethink the way we view non-clinical aspects and prioritise them alongside clinical aspects with similar levels of supervision. This study supports the work by Yardley et al advocating for independence and graduated responsibility for trainees during $\mathrm{HST}^{21}{ }^{21}$ However, also teaching trainees about the potential psychological impact of final responsibility, something very difficult to understand until one is actually within the consultant role. ${ }^{21}$

It is important to recognise that changing the focus in one area may impact on another area. There is only a defined period of time for training and curriculum planners ultimately need to ensure all of the competencies are met to the required standard. 
Table 2. To what extent did participants agree with the following statements

Statement

Acting up as the consultant has helped me feel prepared for the consultant role

Good access to specialist clinics helped prepare me for the clinical aspects of the consultant role

Prior practical experience of an aspect of management (eg service development, change management, governance) prepared me for that aspect of the consultant role

There is a need for practical experience of the non-clinical aspects of the consultant role

Attending a management course was not where I learnt the management aspects of the consultant role

Management courses were useful in learning the theory of management

Attending management meetings (eg implementation, governance, directorate, strategy) were useful in preparation for the consultant role

Attending the consultant meetings would help prepare me for the consultant role

I found it useful working in different services to observe the variety of ways services are run

Shadowing individuals in senior management roles was helpful in preparation to be a consultant

In hindsight, as a trainee I did not have a deep understanding of the non-clinical aspects of the consultant role

Opportunities for experience with non-clinical skills are valuable in preparation to be a consultant

Senior encouragement to be involved with non-clinical skills was valuable in preparing me for the consultant role

Dedicated time, within the rota, to learn management during higher specialty training would be helpful

Some aspects of the consultant role are difficult to prepare for and you just need to do the job

\begin{tabular}{|c|c|c|c|c|}
\hline SD, n (\%) & D, n (\%) & $A, n(\%)$ & SA, n (\%) & UC, n (\%) \\
\hline 0 & 0 & $2(8)$ & $6(24)$ & $17(68)$ \\
\hline 0 & $2(8)$ & $8(33)$ & $13(54)$ & $1(4)$ \\
\hline 0 & $2(8)$ & $14(56)$ & $7(28)$ & $2(8)$ \\
\hline 0 & 0 & $5(20)$ & $20(80)$ & 0 \\
\hline 0 & $3(12)$ & $11(44)$ & $10(40)$ & $1(4)$ \\
\hline 0 & $4(16)$ & $17(68)$ & $3(12)$ & $1(4)$ \\
\hline 0 & 0 & $13(52)$ & $10(40)$ & $2(8)$ \\
\hline 0 & 0 & $8(32)$ & $17(68)$ & 0 \\
\hline 0 & 0 & $6(24)$ & $17(68)$ & $2(8)$ \\
\hline 0 & 0 & $7(28)$ & $8(32)$ & $10(40)$ \\
\hline $1(4)$ & $6(24)$ & $10(40)$ & $8(32)$ & 0 \\
\hline 0 & 0 & $6(25)$ & $18(75)$ & 0 \\
\hline 0 & 0 & $12(50)$ & $10(42)$ & $2(8)$ \\
\hline 0 & 0 & 7 (28) & $18(72)$ & 0 \\
\hline 0 & $4(26)$ & $14(56)$ & $7(28)$ & 0 \\
\hline
\end{tabular}

Median value shown in bold. $\mathrm{A}=$ agree; $\mathrm{D}=$ disagree; $\mathrm{SA}=$ strongly agree; $\mathrm{SD}=$ strongly disagree; $\mathrm{UC}=$ unable to comment.
This is the first study that looks at transition from registrar to consultant in GUM. It is unique in that it goes further than stating which areas consultants feel prepared for but explores the factors that increase levels of preparedness. Further research would be beneficial to look at the optimal ratio of clinical and non-clinical work to optimise feelings of preparedness for the new consultant role while achieving all of the required competencies.

\section{Limitations}

The number of consultants who fit the inclusion criteria was unknown, therefore the worst-case scenario for the response rate was $25 / 60$ (42\%). This is consistent with other study response rates, however, could affect the transferability of the findings. ${ }^{15} \mathrm{~A}$ single researcher conducted the study and ideally a second researcher would be used for data analysis and interpretation. This is mitigated to some degree by using a mixed methods study as qualitative themes could be corroborated or refuted.

\section{Conclusion}

New consultants in general feel better prepared for clinical than non-clinical aspects of the new role. Practical experience was a key element to ensure deep levels of learning but to support this, future trainees need increased responsibility and opportunities for leadership. We must continue to provide a supportive learning environment and consider providing dedicated time for trainees to learn non-clinical skills. By further understanding the factors and processes that positively correlate with preparedness for being a consultant, educators can use this to better prepare individuals for the non-clinical aspects of the role. 


\section{Glossary}

Exploratory sequential mixed methods study: This study design is where an initial qualitative phase is conducted and analysed first, then a second quantitative phase is conducted using the data generated from the first phase; the second phase checks the transferability of the findings from the first phase. ${ }^{23}$

Purposeful sampling strategy: Where the researcher selects the participants based on specific characteristics needed for their sample, for example, in this study to ensure the sample was representative of the UK. ${ }^{24}$

Semi-structured interviews: This is an in-depth interview where the interviewer has an interview schedule with set questions, if the participant goes down a certain tangent the interviewer may also probe further in that direction before coming back to the schedule. $^{24}$

Telephone semi-structured interviews: Semi-structured interviews conducted via the telephone.

Thematic analysis: A process that allows the generation and analysis of patterns or themes within data. ${ }^{25}$

\section{Acknowledgements}

Thank you to the GUM Specialist Advisory Committee for allowing this study to be conducted, to Dr Jackie Sherrard for helping develop the questionnaire and to all of the tutors on the Royal College of Physicians MSc in Medical Education course for their constructive advice throughout the study.

\section{References}

1 Dickson J, Liu D, Bloomfield D. Training in clinical oncology and the transition from trainee to consultant: results of the Royal College of Radiologists' 2015 post-certificate of completion of training survey. Clin Oncol 2017;29:e64-71. www.sciencedirect.com/science/ article/pii/S0936655516303661 [Accessed 19 May 2019].

2 Morrow G, Illing J, Redfern N, Burford B, Kergon C. Are specialist registrars fully prepare for the role of consultant? Clin Teach 2009:6:87-90.

3 Beckett M, Hulbert D, Brown R. The new consultant survey 2005. Emerg Med J 2006;23:461-3.

4 Brown JM, Ryland I, Shaw NJ, Graham DR. Working as a newly appointed consultant: a study into the transition from specialist registrar. Br J Hosp Med 2009;70:410-4.

5 Westerman M, Teunissen PW, Fokkema JPI et al. The transition to hospital consultant and the influence of preparedness, social support, and perception: A structural equation modelling approach. Med Teach 2013;35:320-7.

6 Academy of Medical Royal Colleges, NHS Institute for Innovation and Improvement. Medical Leadership Curriculum. Coventry: NHS Institute for Innovation and Improvement, 2008. www.leader shipacademy.nhs.uk/wp-content/uploads/2012/12/NHSLeadershipLeadership-Framework-Medical-Leadership-Curriculum.pdf [Accessed 19 May 2019].

7 Darzi A. High quality care for all: NHS next stage review final report. Norwich: The Stationary Office, 2008. www.gov.uk/government/ publications/high-quality-care-for-all-nhs-next-stage-review-finalreport [Accessed 19 May 2019].
8 Francis R. Mid-Staffordshire NHS Foundation Trust Public Enquiry. London: Stationary Office, 2013. https://assets.publishing.service. gov.uk/government/uploads/system/uploads/attachment_data/ file/279124/0947.pdf [Accessed 10 December 2019].

9 General Medical Council. Generic professional capabilities framework. London: GMC, 2017. www.gmc-uk.org/-/media/documents/ generic-professional-capabilities-framework-0817_pdf-70417127. pdf [Accessed 19 May 2019].

10 Medical Protection Society. Complaints culture. Medical Protection Society, 2018. www.medicalprotection.org/uk/articles/complaintsculture [Accessed 19 May 2019].

11 Royal College of Physicians. Consultant physicians. RCP, 2015. www.rcplondon.ac.uk/education-practice/advice/consultantphysicians [Accessed 10 December 2019].

12 Clarke J. Medical Foundation for HIV and Sexual Health eFeature. London: MEDFASH, 2015. www.medfash.org.uk/efeature/ efeature-21 [Accessed 19 May 2019].

13 General Medical Council. National training survey: Genito-urinary medicine reports. London: GMC, 2018.

14 Ellen M. Personal correspondence to Sophie Flavell. 09 May 2019.

15 Dijkstra IS, Pols J, Remmelts P, Brand PLP. Preparedness for practice: A systematic cross-specialty evaluation of the alignment between postgraduate medical education and independent practice. Med Teach 2015;37:153-61.

16 Morrow G, Burford B, Redfern N, Briel R, Illing J. Does specialty training prepare doctors for senior roles? A questionnaire study of new UK consultants. Postgrad Med J 2012;88:558-65.

17 Westerman M, Teunissen PW, Jorgensen RL et al. The transition to hospital consultant: Denmark and the Netherlands compared on preparedness for practice, perceived intensity and contextual factors. Med Teach 2013;35:481-9.

18 Joint Royal Colleges of Physicians Training Board. Specialty training curriculum for genitourinary medicine. London: JRCPTB, 2016. www.jrcptb.org.uk/sites/default/files/2016\% 20GUM\% 20 Curriculum \% 20FINAL.pdf [Accessed 19 May 2019].

19 Kolb DA. Experiential learning: Experience as a source of learning and development. Englewood Cliffs: Prentice Hall, 1984.

20 Dale E. Audio-visual methods in teaching, 3rd edn. New York: Dryden Press, 1969.

21 Yardley S, Westerman M, Bartlett M et al. The do's, don't and don't knows of supporting transition to more independent practice. Perspect Med Educ 2018;7:8-22.

22 Dijkstra IS, Pols J, Remmelts $\mathrm{P}$ et al. How educational innovations and attention to competencies in postgraduate medical education relate to preparedness for practice: the key role of the learning environment. Perspect Med Educ 2015;4:300-7.

23 Creswell JW, Plano Clark VL. Designing and conducting mixed methods research. Thousand Oaks: Sage publications, 2007.

24 Cohen L, Manion L, Morrison K. Research methods in education, 8th edn. Routledge, 2017.

25 Braun V, Clarke V. Using thematic analysis in psychology. Qualitative Research in Psychology 2006;3:77-101.

Address for correspondence: Dr Sophie Flavell, Department of Genitourinary Medicine, Nottingham City Hospital, Hucknall Road, Nottingham NG5 1PB, UK.

Email: sophieflavell@nhs.net 